\title{
Patient satisfaction with the perioperative care by anesthesiologists: pilot study at four surgical departments
}

\author{
Janusz Springer1 ${ }^{\mathbb{D}}$, Karolina Dudzińska1, Monika Nurkowska ${ }^{1}$, \\ Liudmila Hasak², Anna Dylczyk-Sommer² (D)
}

${ }^{1}$ Student Scientific Club at the Department of Anesthesiology \& Intensive Therapy, Medical University of Gdańsk, Poland ${ }^{2}$ Department of Anesthesiology \& Intensive Therapy, Medical University of Gdańsk, Poland

\begin{abstract}
Background: The aim of this pilot study was to measure the outcomes of perioperative care by anesthesiologists and patient satisfaction at four surgical departments. Methods: We designed an original 25-item questionnaire and used it to complete structured interviews of 80 consenting, alert, adult surgical patients during their 1st to 3 rd post-operative day. Results: Although $>70 \%$ were satisfied with the information sharing, $43 \%$ patients were unsure or not informed about the possible complications of anesthesia. Similarly, $>75 \%$ positively rated the anesthesiologists' bedside manner; however $69 \%$ were either unsure or sure that an anesthesiologist did not visit them after surgery. Interestingly, this lack of continued care had no overall effect on patient satisfaction. Majority reported receiving immediate post-operative analgesia (65\%). The Oncological Surgery patients reported highest (and the Orthopedic patients the lowest) satisfaction with their postoperative nausea and pain management. Majority of responders were overall satisfied with their care. Conclusions: Our data indicate a high level of patient satisfaction with nearly all aspects of perioperative anesthesiology care. However, anesthesiologists need to more thoroughly inform patients about possible complications of anesthesia. A larger survey is needed to fully assess the patient care and satisfaction trends discussed above.

Keywords: patient / satisfaction / surgical / perioperative care / anesthesiologist
\end{abstract}

\section{Citation}

Springer J, Dudzińska K, Nurkowska M, Hasak L, Dylczyk-Sommer A. Patient satisfaction with the perioperative care by anesthesiologists: pilot study at four surgical departments. Eur J Transl Clin Med. 2018;1(2):58-63.

DOI: $10.31373 /$ ejtcm/102747

\section{Background}

Due to the technological and pharmacological advancements, major negative clinical outcomes such as mortality, myocardial infarction or brain injury became too rare in anesthesia practice to be analyzed in 
multicenter studies [1]. Furthermore, the clinical outcomes are increasingly being evaluated regarding the patient's quality of life, instead of the technical success of the intervention [2]. Increasing attention is also paid to the patient's informed consent, which according to some authors includes not just consent for the particular procedure but also for specific complications and discomfort associated with the suggested treatment method [3]. Another patient-centered outcome is satisfaction, defined as the degree of compatibility between the patient's expectation and the health care provider's achievement [4]. Therefore, a growing number of anesthesiology research and principles of healthcare management focus on the patient-doctor information sharing, patient patients' quality of life and satisfaction from care received with the goal of increasing the quality of perioperative care.

\section{Aim}

The aim of this pilot study was to measure the outcomes of perioperative care by anesthesiologists and patient satisfaction at four surgical departments of the University Clinical Centre (UCC) in Gdańsk.

\section{Methods}

After a review of literature on anesthesiology satisfaction questionnaires we developed a 25 -item questionnaire. It covered 5 dimensions: preoperative consultation (9 questions), bedside manner (5), pre-operative fear \& discomfort (4), pre \& post-operative care (5) and the overall patient satisfaction (2). To ensure clarity, all questions were neutrally worded and did not contain medical jargon. Except for questions about demographics and specific fear/s, the responses were rated using a 5-point Likert scale [5]. Scores were assigned on the scale as follows: Yes or Very Satisfied (4), Rather Yes or Satisfied (3), Hard to say (2), Rather Not or Dissatisfied (1), No or Very Dissatisfied (0).

After obtaining the permission of the local Bioethics Commission (NKBBN/61/2012), we used the questionnaire to complete systematic, in-person interviews at the bedside of consenting and alert adult patients during their 1st-3rd post-operative day at 4 in-patient surgical departments of the UCC. The interviews were conducted by medical student volunteers, who were not directly involved in the interviewed patient care. A total of 80 interviews were analyzed, twenty from each of the following four departments: General, Endocrine and Transplant Surgery, Oncological Surgery, Orthopedic and Trauma Surgery, Plastic Surgery (Figure 1).
Figure 1. Inclusion of interviews

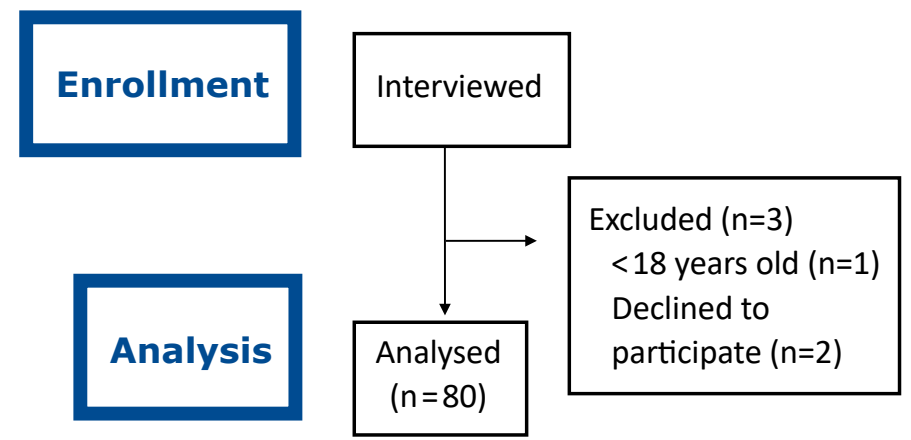

\section{Results}

The majority of our respondents were women (57\%), age 18-65 (78\%), with high-school education (46\%), after general anesthesia (93\%) and with 1-2 previous operations under anesthesia (51\%). Although $>70 \%$ gave high ratings in the information sharing dimension, as many as $43 \%$ (31\% of them were Orthopedic patients) were either unsure or not informed about the possible complications of anesthesia (Figure 1 ). Similarly, $>75 \%$ of the patients positively rated the bedside manner (Figure 2); however the majority (69\%) were either unsure or sure that an anesthesiologist did not visit them in the post-operative period (Figure 3). Interestingly, this lack of continued care had little overall effect on satisfaction scores $(56 \%$ of the patients were "satisfied" and 38\% "very satisfied"). Almost $1 / 3$ of the responders did not report any pre-operative anxiety and majority of them (38\%) were General surgery patients.

Overall, the most commonly reported pre-operative concerns were: fear of post-operative pain $(37 \%)$ and fear of not waking up after the procedure (25\%). Interestingly, our patients were 3 times more likely to worry about a surgeon's error than an anesthesiologist's error ( $18 \%$ and $6 \%$ respectively, Figure 3 ). Majority of patients reported no discomfort due to physical factors such as pre-operative thirst or hunger (62\%), positioning on the operating table (72\%), post-operative nausea or emesis (58\%, Figure 7 ) and majority received immediate post-operative analgesia (65\%, Figure 5). The Oncological Surgery patients reported highest satisfaction with management of their postoperative nausea and pain, while the Orthopedic patients were the least satisfied in this area (Figure 6). Majority of responders were overall satisfied with their care, with those at Plastic surgery clinic slightly in the lead. 


\section{Discussion}

When reading any literature on patient satisfaction with any type of care or medical procedure, one automatically starts to wonder "what exactly is patient satisfaction?" According to an often-cited definition, patient's satisfaction consists of his/her cognitive as- sessment of the received care and the emotional reactions related to it [6]. Other authors indicated that patient satisfaction depends on the consistency between the patient's expectations and actual care $s /$ he received [7]. Fung et al have dissected these concepts down to their elements and accurately described the methodological challenges, if not frustrations, with

Figure 2. Bedside manner

Did the anestesiologist introduce her/himself?

Was s/he friendly?

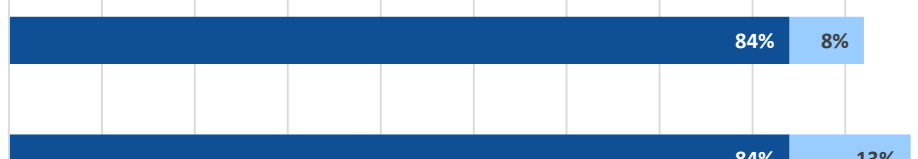

Did you feel comfortable during the consultation?

Did you have a chance to ask questions?

Did you have a chance to inform about your previous anesthesia?

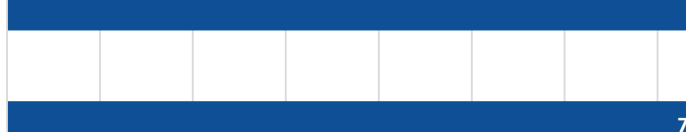

Did anesthesiologist listen to you?

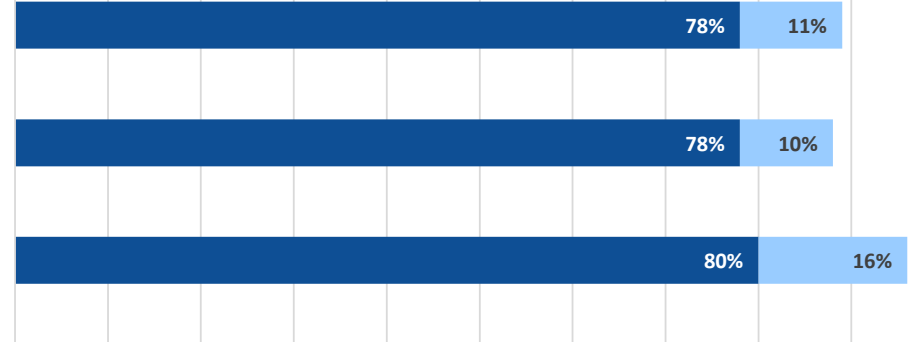

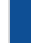

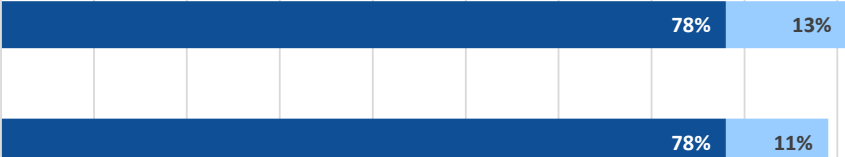

Do you consider pre-op consultation necessary?

(1)

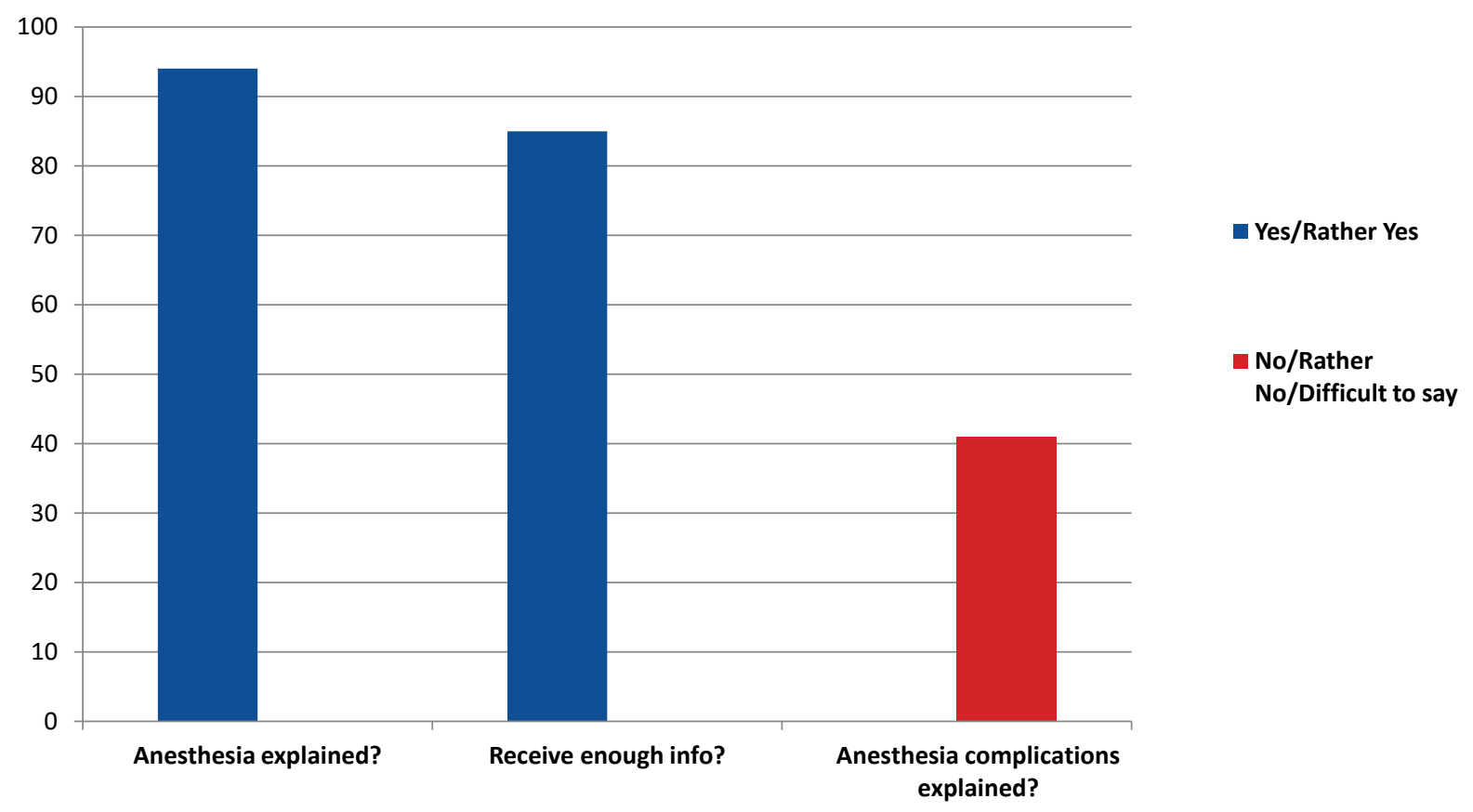


measuring expectations, ability to accept difference between expectations and reality, mental state during satisfaction etc [1]. Clearly satisfaction is not a one-dimensional concept, thus measuring it is not simple and requires appropriate tools. In the past, researchers relied on psychometric methods to design robust questionnaires [8].
Although there are several validated, previously published anesthesia satisfaction questionnaires, we designed our own instrument. The lowa Satisfaction with Anesthesia Scale is a validated psychometric questionnaire, however it was not appropriate for our study because it was designed to measure the satisfaction from monitored anesthesia care only [9]. We decided not to

Figure 4. Pre-operative anxiety. The 4 most commonly mentioned causes of anxiety are listed

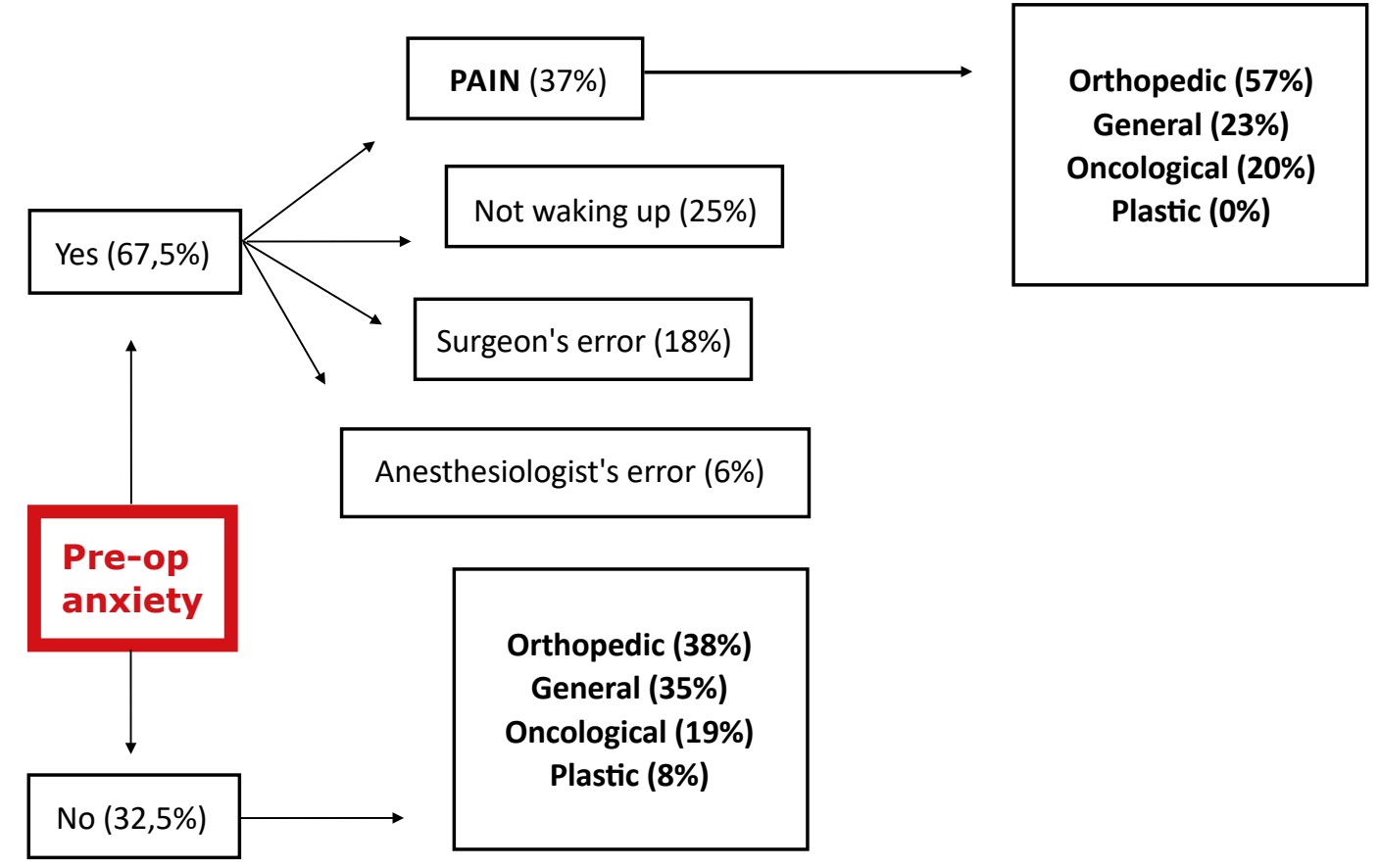

Figure 5. Pre-operative anxiety

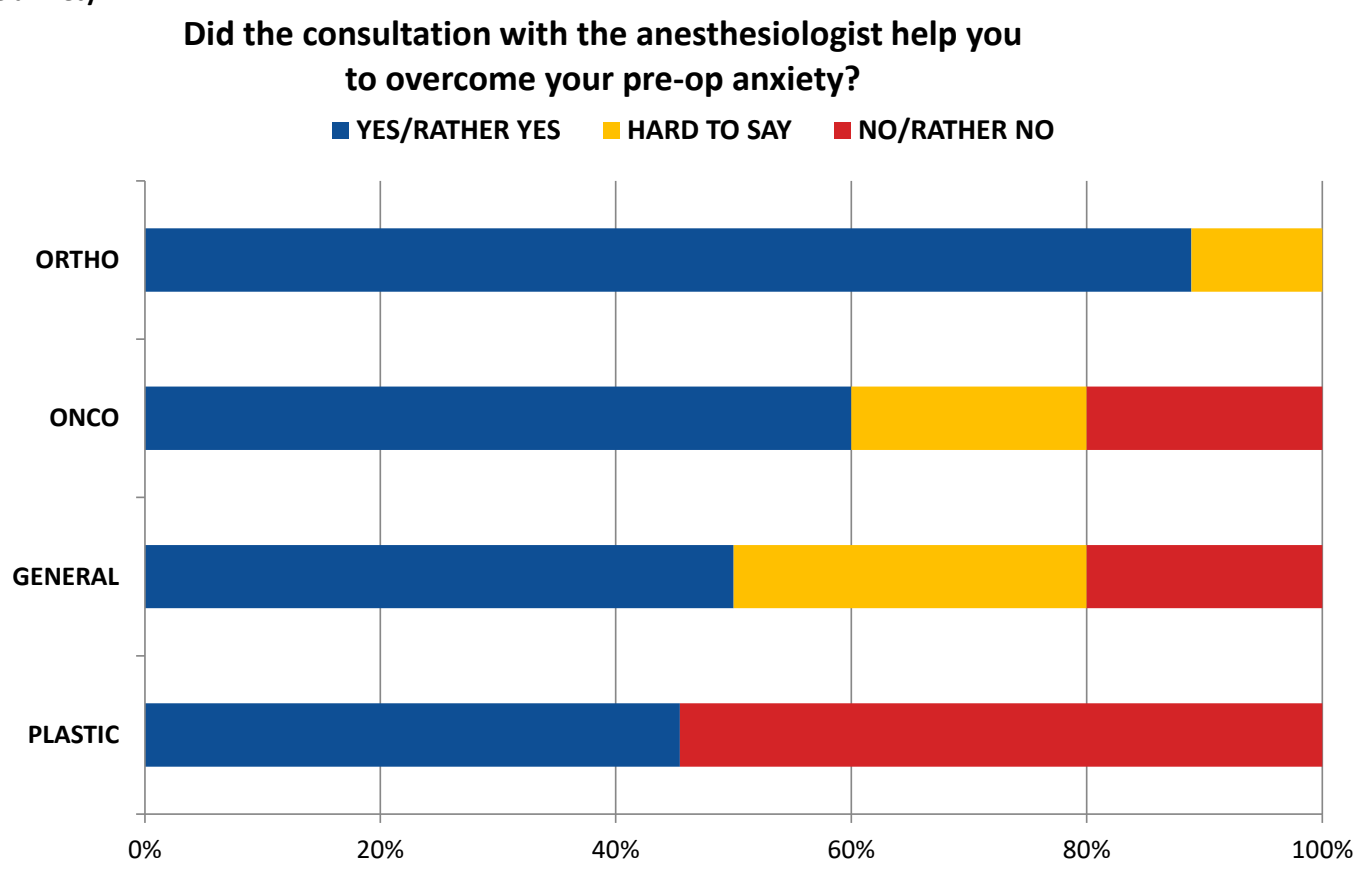


use the Leiden Perioperative care Patient Satisfaction questionnaire because in our opinion it was too lengthy to use during a structured interview [10].

Many of the previously published studies involved staff distributing the questionnaires to the patients at the ward, resulting in response rates between 80 and $100 \%$ [10-11]. To improve the response rate, we conducted systematic, structured interviews using our qu- estionnaire. We feel that the so-called 'halo effect' and underreporting of dissatisfaction has been minimized because the interviews were conducted by medical students who were not involved in the patient care at their respondents' wards. Although this approach has been viewed with some suspicion, we did not obtain the near- $100 \%$ response rates that make the validity of prior studies suspect [1].

Figure 6. Post-operative pain management

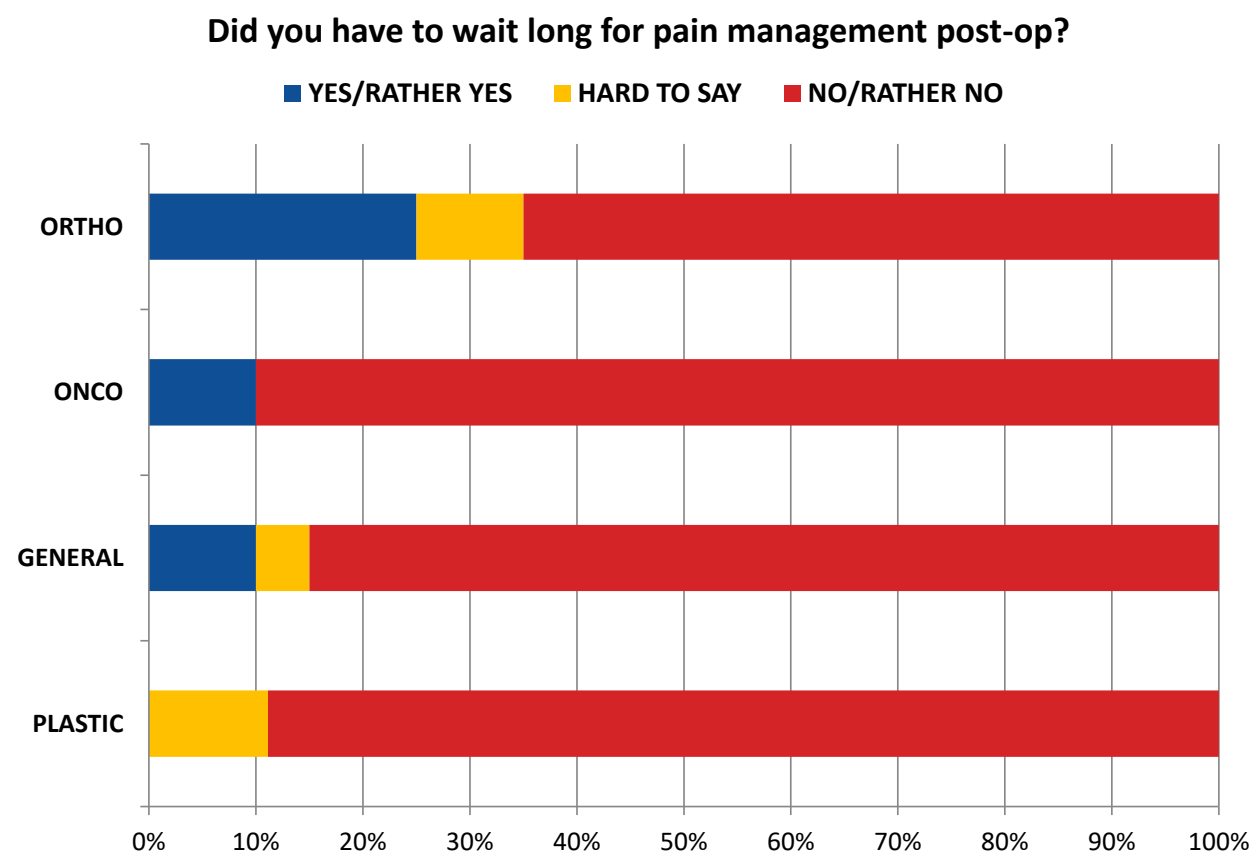

Figure 7. Post-operative discomfort due to nausea \& emesis

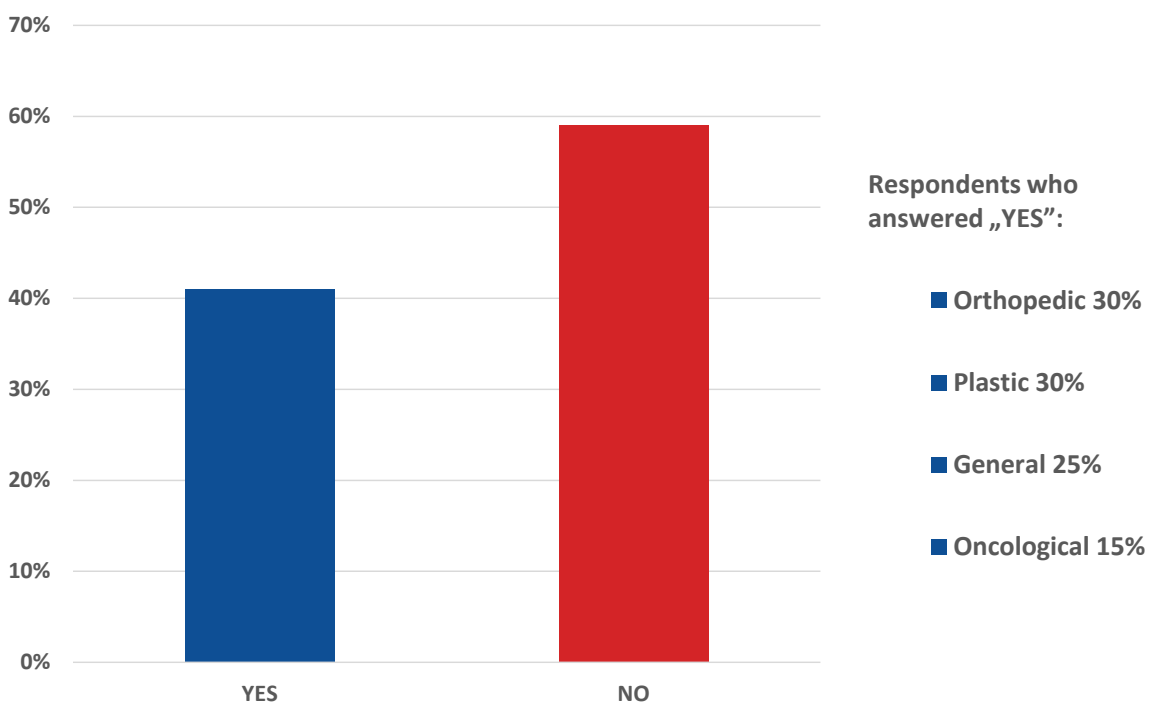


In terms of methodology, a somewhat similar study was performed by Gaszyński et al, who surveyed 42 patients at a general surgery department [12]. Comparing with our results from a general surgery department, Gaszyński et al had significantly more respondents claiming to be uninformed about the possible adverse effects of anesthesia $(52,4 \%$ vs. $10 \%)$ and fearing not waking up after the procedure (58,8\% vs. $30 \%)$ [12]. On the contrary, our general surgery patients much more frequently reported post-operative nausea and emesis than those surveyed by Gaszyński et al ( $40 \%$ vs $20,6 \%$ ) [12].

Our study has several limitations. First of all, our questionnaire was not designed by psychologist. Second, we did not perform a test-retest reliability check or a validity check (no comparison with responses predicted by anesthesiologists or anesthesia nurses). Third, we did not review medical documentation to compare what doses of analgesia our patients received. Fourth, the inclusion of patients who underwent regional (intravenous) anesthesia (7\%) might have confounded our results. Finally, despite our best efforts to minimize response bias (interviews conducted by volunteers, who were not directly involved in patient care), it is possible that some of the patients told us what we wanted to hear. However, we performed this pilot study not only to establish a general trend in responses but specifically to test the methods of data collection and analysis.

Our preliminary results confirm earlier observations that the patient-anesthesiologist communication is a critical element of patient satisfaction with peri- -operative care and the pre-operative visit is particularly important [13-14]. However, a larger survey at more surgical departments combined with a review of medical documentation is needed to fully assess the patient care and satisfaction trends discussed above.

\section{Conclusion}

Our preliminary data suggest a high level of patient satisfaction with nearly all aspects of perioperative anesthesiology care at our institution. However, anesthesiologists need to more thoroughly inform patients about possible complications of anesthesia. It is critical to respect the patient's right to information about the procedure and its complications. Surveys are a simple and useful tool to measure quality of care indicators at an anesthesiology department and can help in training residents. A larger survey at more surgical departments is needed to fully assess the patient care and satisfaction trends discussed above.

\section{Acknowledgements}

The authors would like to thank Anna Smeja MD and Joanna Woźniak MD for collecting and processing the survey data for this study. Last but not least, we would also like to thank Małgorzata Omilian-Mucharska MSc for valuable help with figure design.

\section{References}

1. Fung D, Cohen MM. Measuring Patient Satisfaction with Anesthesia Care. Anesth Analg. 1998;87(5):1089-98.

2. Gabel R. The Ethics of Managed Care. ASA Newsletters. 1996;(60):16-20

3. Suchorzewska J, Basińska K. Informed consent in anaesthesiological practice. Anaesthesiol Intensive Ther. 2006;38(4):243-6.

4. Vetter TR, Ivankova N V, Pittet J-F. Patient satisfaction with anesthesia: beauty is in the eye of the consumer. Anesthesiology. 2013;119(2):245-7.

5. Likert R. A technique for the measurement of attitudes. Arch Psychol. 1932;22(140):55.

6. Pascoe GC. Patient satisfaction in primary health care: a literature review and analysis. Eval Program Plann. 1983;6(3-4):185-210.

7. La Monica EL, Oberst MT, Madea AR, Wolf RM. Development of a patient satisfaction scale. Res Nurs Health. 1986;9(1):43-50.

8. Chanthong P, Abrishami A, Wong J, Herrera F, Chung F. Systematic review of questionnaires measuring patient satisfaction in ambulatory anesthesia. J Am Soc Anesthesiol. 2009;110(5):1061-7.

9. Dexter F, Aker J, Wright WA. Development of a measure of patient satisfaction with monitored anesthesia care the lowa satisfaction with anesthesia scale. Anesthesiol J Am Soc Anesthesiol. 1997;87(4):865-73.

10. Caljouw MAA, Van Beuzekom M, Boer F. Patient's satisfaction with perioperative care: development, validation, and application of a questionnaire. Br J Anaesth. 2008;100(5):637-44.

11. Baroudi DN, Nofal WH, Ahmad NA. Patient satisfaction in anesthesia: A modified lowa Satisfaction in Anesthesia Scale. Anesth essays Res. 2010;4(2):85.

12. Gaszyński T, Jakubiak J, Woźniak K, Trafidło T, Ratajczyk P, Gaszyński W. Badanie satysfakcji chorych i ich opinii na temat jakości świadczeń anestezjologicznych w świetle objawów niepożądanych znieczulenia Anestezjologia Íntensywna Terapia, 2011. Anaesthesiol Intensive Ther. 2011;XLIII(4):214-9.

13. Kopp VJ. Communication with patients before anesthesia and obtention of preanesthetic consent. Curr Opin Anesthesiol. 2002;15(2):251-5.

14. Harms C, Nübling M, Langewitz W, Kindler $\mathrm{CH}$. Patient satisfaction with continued versus divided anesthetic care. J Clin Anesth. 2007;19(1):9-14. 